\title{
No safe radiation, expert says
}

$\mathrm{D}$ aniel Rudka looks like he's a nuclear bomb survivor. Wrinkled, milky scars flow up his arms past his neck and discolour his pockmarked face. He walks with a cane, because he can't always trust his radiation-weakened bones to keep him upright.

But Rudka is not the victim of a nuclear bomb, accident or meltdown. In fact, he's never even been involved with any manner of power plant mishap. He simply used to work at a plant in Port Hope, Ontario, that constructs fuel rods for nuclear reactors. But at one point, he spent three weeks scooping powdered uranium with a plastic bucket that might have been obtained from an ice machine, while wearing a T-shirt, coveralls cut off at the bicep and plastic gloves that weren't lead-lined.

"You didn't have to bomb me to still have the same effect," he says.

Whether it comes from nuclear weapons or nuclear power, radiation's effects on the human body are the same, veteran antinuclear campaigner Dr. Helen Caldicott told a Mar. 26 conference organized by Physicians for Global Survival Canada.

No radiation is safe, the 73-year-old Australian physician and author argued during a "Facing off for Social Justice in a Militarized World" session of the conference, which explored issues ranging from handling radioactive waste to the public health consequences of radiation leaks, such as those now being experienced at the Fukushima Nuclear Plant complex in the wake of the earthquake and tsunami which devastated parts of northern Japan.

Caldicott called radioactive waste one of the major unaddressed problems associated with nuclear reactors.

"There's no container that can hold radioactive waste for more than a hundred years. Concrete cracks, plastics are no good, and iron disintegrates as it rusts," she told the conference.

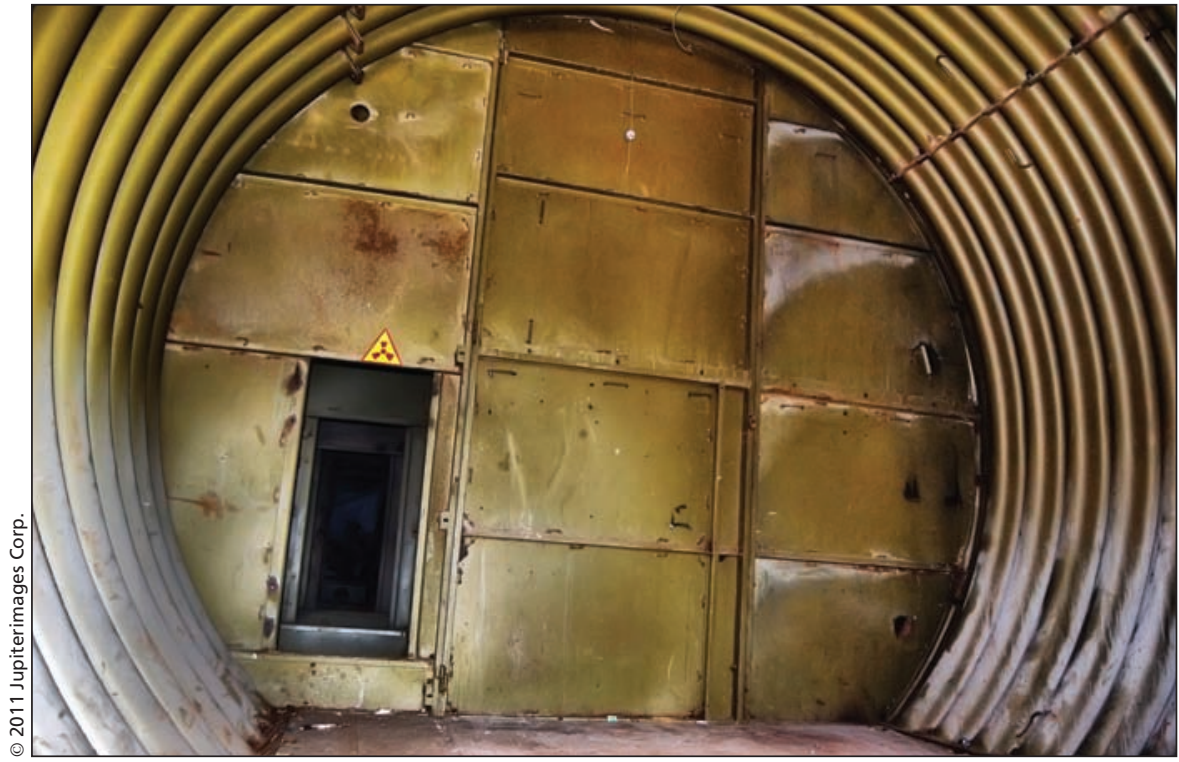

"There's no container that can hold radioactive waste for more than a hundred years Concrete cracks, plastics are no good, and iron disintegrates as it rusts," says antinuclear advocate Dr. Helen Caldicott.

But radon is highly soluble, and once it leaks into the ecosystem, the radiation becomes bio-concentrated as it moves up through the food chain. It is also cumulative, meaning that later generations are more likely to experience the effects.

Caldicott cited Fallujah, Iraq, where it is alleged that the United States and United Kingdom used depleted uranium ammunitions during a 2004 raid, as an example of the long-term consequences. Fallujah's recorded birth defects have become so prevalent that $80 \%$ of babies are born as cyclops, Caldicott said, adding that doctors have told women to stop having children.

Although the International Atomic Energy Agency promotes nuclear reactors as a clean, green and safe solution to the ever-increasing global need for electricity, exalting nuclear reactors, while condemning nuclear weapons is hypocritical, Caldicott added. "They say: 'You can have a nuclear reactor but you mustn't build a bomb. We've got all the bombs and you can't have them. But here's a bomb factory'."
Caldicott argued that government should take the money spent on nuclear power - $\$ 12$ billion to $\$ 15$ billion per reactor - and use it to refit all homes and buildings with solar panels.

Dr. Michael Dworkind, president of Physicians for Global Survival Canada, echoed the call for the elimination of both nuclear reactors and nuclear weapons, saying it would be "the ultimate in preventive medicine."

The health consequences of radiation poisoning, which have long been demonstrated, can include hair loss, recurring infections, anemia, weight loss and cancer.

Rudka, who worked at the Port Hope plant, then called Zircatec, from 1993 to 1995 , says he still periodically vomits in the mornings as his body goes through "stages of decay."

His is a classic case of the consequences of exposure to radiation and another example of why "nuclear is not the answer," Caldicott said. - Sabrina Doyle, Ottawa, Ont.

CMAJ 2011. DOI:10.1503/cmaj.109-3852 